\title{
Quality of Leader-Member Relationships in Saudi Arabia: Nursing Perspectives
}

\author{
Alaa Ali Alharbi ${ }^{*}$, Fatma M. Baddar2,3 \\ ${ }^{1}$ MSc Nursing Administration, Quality Analyst, Quality Improvement, Patient Safety \& Risk Management, King Abdulaziz Hospital, \\ Jeddah, Saudi Arabia \\ ${ }^{2}$ Associate Professor, Nursing Administration \& Education Department, College of Nursing, King Saud University, Riyadh, Saudi \\ Arabia \\ ${ }^{3}$ Nursing Administration Department, Faculty of Nursing, Alexandria, Egypt \\ ${ }^{*}$ Corresponding Author \\ Alaa Ali Alharbi
}

Article History

Received: 16.10 .2019

Accepted: 24.10 .2019

Published: 05.11 .2019

\begin{abstract}
Background: High-quality leader-member relationships (LMRs) assist employee readiness for greater responsibilities beyond one's main job descriptions. This is to better contribute to other aspects or units within the organization. The Saudi Ministry of Health focuses on building human resources development to achieve improved organizational performance. Unfortunately, few studies have examined the Saudi Arabian healthcare sector's handling of LMRs. Objectives: The goal of the present study was to explore LMR levels and whether a nurse's work position influences LMRs within a university-affiliated hospital. Methods: A cross-sectional descriptive method was used and applied to a sample of 538 nursing staff. A self-report questionnaire was adopted for analysis Results: Results revealed that "Respect," "Affect," and "Contribution" dimensions were high perceived while the "Loyalty" moderate perceived. The association between overall LMR perception and current position was statistically significant $(p=0.012)$. Discussion: Sustainability of an LMR should be promoted where functioning and overall performance need to be enhanced. Conclusion: LMRs were modestly present within the current study, where the Respect dimension was perceived most highly among nurses, with Loyalty having the least positive perception. However, the Affect and Contribution dimensions were also perceived positively. The present findings also indicate that nurse managers' perceptions were higher than those of bedside nurses.
\end{abstract}

Keywords: Leader-member relationship, Affect, Contribution, Loyalty, Respect.

\section{INTRODUCTION}

Currently, the world is moving towards a single market system that is enhanced by reduced travel, trade, and other economic barriers. This market system is boosted by increased integration of people from different parts of the world, both physically and through online technologies [1]. One significant impact of this trend is increased competition among organizations. In order to achieve a high level of competitiveness and fit this new world market system, organizations need to adopt new behaviors that can improve individual and corporate efficiency. Specifically, service-based organizations, such as healthcare providers, are increasingly seen as stable and highly profitable firms [2]. Here, there is an increased demand for employees who are willing to extend their work beyond the traditional job description [3]. Hospitals can be one of the more inspiring business environments with which to work. This requires vital attention paid to subtle problems facing patients. At the core of such activities are nurses who ensure accommodations to a patient's needs. Therefore, hospitals present a viable workplace for addressing leader-member relationships (LMRs).

In Saudi Arabia, the healthcare sector is showing dynamic improvements, especially in nursing services. Many government, as well as private, healthcare organizations have shown improvements in patient care quality and have been accredited by reputable organizations, including the Joint Commission International Accreditation (JCIA). Due to reform plans implemented by the Saudi Ministry of Health $(\mathrm{MOH})$, human resources development and organizational culture enhancement have improved organizational performance. In this context, it is unfortunate that few studies have examined LMRs within the Saudi Arabian healthcare sector. Here, significant knowledge could fill an important gap in how employee-leader interactions help and hinder quality care outcomes.

Copyright @ 2019: This is an open-access article distributed under the terms of the Creative Commons Attribution license which permits unrestricted use, distribution, and reproduction in any medium for non commercial use (NonCommercial, or CC-BY-NC) provided the original author and source are credited. 


\section{LITERATURE REVIEW}

LMR theory discusses the dynamic two-way relationship between leaders and followers [4], showing that leaders develop different quality relationships with those they manage, which predicts subordinates' performance. The theory proposes that leaders should develop an exchange with workplace subordinates. These relationships often determine organizational direction through the allocation of resources, subordinates' responsibilities, decision-making, and overall performance [5]. Liden and Maslyn observed that a four-dimensional LMR model includes the following domains: Contribution, Loyalty, Affect, and Professional Respect [6].

Affect is defined as the mutual affectation between members of a dyad that is based mainly on interpersonal desirability rather than work or professional values. This type of affection manifests as friendship through rewarding components and outcomes [6]. Loyalty refers to the support for goals and personal character inherent within the other member of the LMR dyad [6]. Contribution reflects the input of work-oriented activities that facilitate mutually explicit or implicit goals within the dyad. Here, it is necessary to evaluate such activities where the subordinate handles extra responsibilities and completes tasks beyond his/her job description. Likewise, the supervisor provides resources and opportunities that help the subordinate complete those activities [6]. Professional Respect reflects the reputation that is inherent within each member of the dyad within and outside the work organization. This respect may be based on personal experience of the individual, comments made about the person from individuals within or outside the organization, and awards or other professional recognition achieved by the individual. Thus, it is possible to develop a perception of professional respect even before working with—or even meeting—that person [6].

LMRs can prompt subordinates to act more satisfactorily, beyond their roles, within a hospital [7]. According to Leow and Khong, supervisors advance different types of associations with their subordinates [8]. The quality of these relationships determines many features, including the amount of physical or mental effort subordinates bring to their tasks, material resources, information, and social support exchanged between the supervisor and subordinates. This leads to the formation of an LMR process [9]. The first stage primarily involves work socialization, which is followed by a quality LMR. The next stage is the creation of a prescriptive approach for building long-term positive relationships. The last stage must assess the group and network levels [10].

The main purpose of the present study was to explore LMRs and whether predetermined characteristics among nursing personnel (i.e., work position) influenced these relationships. To accomplish this, the present study identified LMR levels as perceived by nursing staff.

The aim of the study was to explore the LMR level as perceived by nursing staff, and whether there is a positive correlation between the work position as a work related factor and the LMR in one of the university-affiliated hospitals.

\section{Material AND Methods \\ Study Design}

According to Polit and Beck, quantitative research focuses on gathering numerical data and generalizing this data across groups of people; descriptive research seeks to describe the status of identified variables [11]. The present study was designed to provide systematic information regarding the LMR phenomenon, where a cross-sectional descriptive design was used to describe nurses' perceptions of LMRs.

\section{Population and Setting}

The study was conducted at one university hospital in Saudi Arabia. Here, all inpatient wards and units, critical care units, and emergency units were assessed. The hospital was selected based on the following criteria: the largest educational governmental hospital that is accredited by the JCIA with a 780-bed capacity and offers distinguished healthcare services through qualified healthcare professionals, specifically nursing personnel. This hospital is also very technologically advanced in order to provide quality care services. This hospital was also assumed to have an active leadership role in nationwide hospital decision-making structures and processes, thus making it an appropriate setting for conducting the present study.

\section{Sampling Technique}

The target sample for this study consisted of all registered nurses who worked in the King Saud University Medical City (KSUMC). However, the accessible sample was further identified according to inclusion criteria that considered: (1) a registered nurse working in either a bedside or administrative position; (2) completed at least six months of service (to ensure that participants had at least some familiarity with the job and organization); and (3) willing to participate. Participants who met the inclusion criteria were invited to be part of the research sample, which included 1,961 nurses distributed across 10 departments: Inpatient - Medical department; Surgical department; Obstetrics and gynecology department; Pediatric department; Operation room department; Intensive care unit department; Oncology department; Specialized unit; Emergency department; and Cardiac department.

\section{Sample Size}

A non-probability quota technique was used to draw the sample. This method of sampling was chosen in order to obtain the maximum benefit of assessing a large number of participants within a limited period [12]. From the accessible sample, all nurse 
managers $(n=90)$ and a quota sample from the accessible staff nurses $(n=1,871)$ was considered for data collection. For staff nurses, the calculation of the sample size was based on the $\mathrm{G}^{*}$ power 3.0 program, where the total number needed was 455 participants based on criteria of a medium effect size (0.4), a level of significance (a) of .05 , and a test power (1- $\beta$ ) of 0.95 . Given that the inclusion of participants was based on convenience, the sample was further increased by $15 \%$ to make sure that contingencies such as non-responses and potential drop-outs were taken into consideration. This brought the final sample size to 525 nurses and 90 nurse managers.

\section{Data Collection Tool}

A self-report questionnaire was adopted for data collection. The questionnaire comprised two main parts: a set of selected demographic characteristics (age, gender, and educational level) and work setting and number of years spent in the current position. The second part was adopted to explore LMRs among nursing personnel. The LMR measure was a 12-item scale for staff to assess their immediate manager or team leader and for a supervisor to assess subordinates. The scale was initially developed by Liden and Maslyn [6]. The measure was scored on a 5-point Likert scale, ranging from $1=$ strongly disagree to $5=$ strongly agree. A high score indicates a quality LMR, and a low score indicates a poor LMR. The scale also includes four dimensions: Respect (items 1, 8, 12), Loyalty (items 2, 5, 9), Affect (items 3, 6, 10), and Contribution (items 4, 7, 11). Scoring criteria were classified by mean results, where the value ranged between 4.20 and 5.00 (Strongly agree), $3.40<4.20$ (Agree), $2.60<3.40$ (Neutral), $1.80<2.60$ (Disagree), and 1.00 $<1.80$ (Strongly disagree). Therefore, strongly agree and agree scores indicated the perception of a high quality LMR, a neutral score represented a moderately positive LMR, while disagree and strongly disagree scores represented a poorly perceived LMR.

A pilot study was performed to evaluate the suitability and reliability of the questionnaire, where 10 to 15 minutes was needed to complete all measures. The LMR sub-scales showed high-reliability, with Liden and Maslyn (1998) observing Cronbach's alpha values for the full scale ranging from .80 to .92 , as compared to current study value of .83 [6].

\section{Ethical Consideration}

Data collection progressed based on official approval obtained from the authors who developed the LMR scale, and we modified the scale for the present Saudi sample. Written informed consent was obtained prior to any data collection. Participants then completed the self-report questionnaires. A representative within each work unit clarified the purpose of the study and informed participants that they could refuse to take part at any time without adverse consequences. Questionnaires were collected during a 3 to 4-week period. After receiving responses, data extracted from the surveys were edited and coded. The Statistical Package for Socia Sciences (SPSS $®$ version 24.0 ) program was used for all data analyses.

Official written consent to conduct the study was obtained from the administration and research/ethical committee in selected settings with reference number (17/0944/IRB) on November 23, 2017. Confidentiality was considered through the expectation that participant information would not be disclosed to others, as stated by American Health Care Association [13]. All participants were verbally reassured regarding the confidentiality of the information provided.

\section{RESULTS}

Total response rate was $91 \%$, with 463 staff nurses and 75 nurse managers providing valid data. About half of the participants $(57.4 \%)$ worked in general wards, nearly a quarter $(24.9 \%)$ worked in the ICU, and $17.7 \%$ worked in the emergency unit. Nearly half of the respondents (43.5\%) were between 30 and 40 years old, $34.2 \%$ were under 30 years old, and $22.3 \%$ were over 40 years old. Most participants were women (88.5\%). A little over a third of the participants (37.2\%) had fewer than 10 years' experience, $36.6 \%$ had over 15 years' experience, and $19.5 \%$ had 10 to 15 years' experience. Most participants worked at the bedside ( $86.1 \%)$, while only $13.9 \%$ were a first line manager.

Table 1 shows detailed frequencies, percentages, means, and standard deviations for each item of the LMR scale. The "Respect" dimension was perceived the most positively $(4.04 \pm 0.63)$ where the phrase "I respect my manager's knowledge of, and competency on, the job" being the highest scored item (4.29 \pm 0.69$)$. "I am impressed with my manager's knowledge of his/her job" was rated the lowest $(3.88 \pm 0.78)$. "Loyalty" was perceived as moderately positive $(3.39 \pm 0.71)$ where the phrase "My manager would come to my defense if I was 'attacked' by others" was rated the highest $(3.72 \pm 0.84)$ while the phrase "My manager defends (would defend) my work actions to a superior, even without complete knowledge of the issue in question" was rated the lowest (2.94 \pm 1.02).

The "Affect" dimension was perceived quite positively $(3.66 \pm 0.69)$ where the phrase "I like my manager very much as a person" was rated the highest $(3.84 \pm 0.77)$ while the phrase "My manager is much fun to work with" was rated the lowest $(3.38 \pm$ 0.85). The "Contribution" dimension was also perceived positively $(3.66 \pm 0.71)$ where the phrase "I do work for my manager that goes beyond what is expected of me in my job" was rated the highest $(3.67 \pm 0.85)$ while the phrase "I do not mind working my hardest for my manager" was rated the lowest $(3.63 \pm 0.92)$. 
Table-1: LMR as perceived by the study participants ( $\mathrm{N}=538)$

\begin{tabular}{|c|c|c|c|c|c|c|c|c|c|c|c|c|c|c|}
\hline \multirow[t]{3}{*}{$\mathrm{N}$} & \multirow{3}{*}{ Items } & \multicolumn{10}{|c|}{ Response } & \multirow{3}{*}{ Mean } & \multirow{3}{*}{ SD } & \multirow{3}{*}{ Ranking } \\
\hline & & \multicolumn{2}{|c|}{$\begin{array}{l}\text { Strongly } \\
\text { Agree }\end{array}$} & \multicolumn{2}{|c|}{ Agree } & \multicolumn{2}{|c|}{ Neutral } & \multicolumn{2}{|c|}{ Disagree } & \multicolumn{2}{|c|}{$\begin{array}{l}\text { Strongly } \\
\text { disagree }\end{array}$} & & & \\
\hline & & $\mathrm{F}$ & $\%$ & $\mathrm{~F}$ & $\%$ & $\mathrm{~F}$ & $\%$ & $\mathrm{~F}$ & $\%$ & $\mathrm{~F}$ & $\%$ & & & \\
\hline \multicolumn{15}{|c|}{ Respect } \\
\hline 1 & $\begin{array}{l}\text { Respect manager's knowledge of, } \\
\text { and competence on, the job. }\end{array}$ & 220 & 40.9 & 261 & 48.5 & 51 & 9.5 & 5 & 0.9 & 1 & 0.2 & 4.29 & 0.69 & 1 \\
\hline 8 & Admire manager's professional skills. & 113 & 21.0 & 299 & 55.6 & 115 & 21.4 & 9 & 1.7 & 2 & 0.4 & 3.95 & 0.72 & 2 \\
\hline 12 & $\begin{array}{r}\text { Impressed with manager's knowledge } \\
\text { of his/her job. }\end{array}$ & 107 & 19.9 & 287 & 53.3 & 125 & 23.2 & 13 & 2.4 & 6 & 1.1 & 3.88 & 0.78 & 3 \\
\hline \multicolumn{12}{|c|}{ Mean for dimension } & 4.04 & 0.63 & - \\
\hline \multicolumn{15}{|c|}{$\begin{array}{l}\text { Loyalty } \\
\end{array}$} \\
\hline 2 & $\begin{array}{l}\text { Manager would defend me to others } \\
\text { in the organization if I made an } \\
\text { explicit mistake. }\end{array}$ & 68 & 12.6 & 230 & 42.8 & 169 & 31.4 & 57 & 10.6 & 14 & 2.6 & 3.52 & 0.93 & 2 \\
\hline 5 & $\begin{array}{l}\text { Manager would come to my defense } \\
\text { if I were "attacked" by others. }\end{array}$ & 77 & 14.3 & 282 & 52.4 & 136 & 25.3 & 36 & 6.7 & 7 & 1.3 & 3.72 & 0.84 & 1 \\
\hline 9 & $\begin{array}{r}\text { Manager defends (would defend) } \\
\text { work actions to a superior, even } \\
\text { without complete knowledge of the } \\
\text { issue in question. }\end{array}$ & 36 & 6.7 & 123 & 22.9 & 188 & 34.9 & 157 & 29.2 & 34 & 6.3 & 2.94 & 1.02 & 3 \\
\hline \multicolumn{12}{|c|}{ Mean for dimension } & 3.39 & 0.71 & - \\
\hline \multicolumn{15}{|c|}{ Affect } \\
\hline 3 & $\begin{array}{r}\text { Manager is the kind of person I would } \\
\text { like to have as a friend. }\end{array}$ & 95 & 17.7 & 256 & 47.6 & 147 & 27.3 & 36 & 6.7 & 4 & 0.7 & 3.75 & 0.85 & 2 \\
\hline 6 & $\begin{array}{r}\text { I like my manager very much as a } \\
\text { person. }\end{array}$ & 96 & 17.8 & 282 & 52.4 & 140 & 26.0 & 16 & 3.0 & 4 & 0.7 & 3.84 & 0.77 & 1 \\
\hline 10 & Manager is a lot of fun to work with. & 40 & 7.4 & 206 & 38.3 & 221 & 41.1 & 62 & 11.5 & 9 & 1.7 & 3.38 & 0.85 & 3 \\
\hline \multicolumn{12}{|c|}{ Mean for dimension } & 3.66 & 0.69 & - \\
\hline \multicolumn{15}{|c|}{$\begin{array}{cc}\text { Contribution } \\
\end{array}$} \\
\hline 4 & $\begin{array}{r}\text { Do not mind working hardest for my } \\
\text { manager. }\end{array}$ & 84 & 15.6 & 241 & 44.8 & 155 & 28.8 & 47 & 8.7 & 11 & 2.0 & 3.63 & 0.92 & 3 \\
\hline 7 & $\begin{array}{l}\text { Do work for my manager that goes } \\
\text { beyond what is expected of me in my } \\
\text { job. }\end{array}$ & 76 & 14.1 & 259 & 48.1 & 164 & 30.5 & 30 & 5.6 & 9 & 1.7 & 3.67 & 0.85 & 1 \\
\hline 11 & $\begin{array}{r}\text { Willing to apply extra effort, beyond } \\
\text { those normally required, to meet my } \\
\text { manager's work goals. }\end{array}$ & 78 & 14.5 & 251 & 46.7 & 163 & 30.3 & 42 & 7.8 & 4 & 0.7 & 3.66 & 0.85 & 2 \\
\hline \multirow{2}{*}{\multicolumn{12}{|c|}{ Mean for dimension }} & 3.66 & 0.71 & - \\
\hline & & & & & & & & & & rall $r$ & ean & 3.69 & 0.58 & - \\
\hline
\end{tabular}

To determine if there were statistically significant differences between participants' perception of LMRs according to their current position, independent samples t-tests were performed (Table-2). Overall, LMR perception was high for both nurse managers (3.84 \pm 0.51$)$ and staff nurses (3.66 \pm 0.59$)$. The association between overall perceptions and current position was statistically significant $(p=0.012)$, which was reflected in all LMR dimensions except for "Loyalty" $(p=0.192)$. Moreover, the findings revealed that nurse managers' perceptions were more positive than bedside nurses. Here, the "Respect" dimension was particularly perceived more positively among nurse managers than bedside nurses $(4.19 \pm 0.63)$ and $(4.02 \pm 0.62)$, respectively. The "Loyalty" dimension was perceived least positively by both nurse managers and bedside nurses $(3.49 \pm 0.68)$ and $(3.38 \pm 0.71)$, respectively.

Table-2: Independent samples t-tests results comparing LMRs according to current position ( $N=538)$

\begin{tabular}{|l|l|l|l|l|}
\hline \multirow{2}{*}{ Dimensions } & Perception according to position & t-test & p- value* \\
\cline { 2 - 3 } & First line manager $(\mathbf{n}=\mathbf{7 5})$ & Nurses $(\mathbf{n}=\mathbf{4 6 3})$ & & \\
\hline Respect & $4.19 \pm 0.63$ & $4.02 \pm 0.62$ & 2.160 & $0.031^{*}$ \\
\hline Loyalty & $3.49 \pm 0.68$ & $3.38 \pm 0.71$ & 1.307 & 0.192 \\
\hline Affect & $3.83 \pm 0.61$ & $3.63 \pm 0.70$ & 2.395 & $0.017^{*}$ \\
\hline Contribution & $3.86 \pm 0.62$ & $3.62 \pm 0.72$ & 2.731 & $0.007^{* *}$ \\
\hline Overall & $3.84 \pm 0.51$ & $3.66 \pm 0.59$ & 2.531 & $0.012^{*}$ \\
\hline
\end{tabular}

*indicates significant finding at $p \leq 0.05 ;{ }^{*}$ indicates significant finding at $p \leq 0.001$ 


\section{Discussion}

Positive perceptions regarding LMRs could be attributed to the fact that nurses have insights into the importance of forming organizational performance and success through positive relationships between leaders and subordinates, which has been emphasized elsewhere [14-17]. Regarding attempts to encourage quality LMR development, Chen et al., and Organ and Konovsky claim that organizations gain much from an improved understanding of how employees and their supervisors perceive LMRs [18, 19]. This should result in constructive outcomes for individuals and the organization, whereby nurses with high-quality LMRs readily take greater responsibilities while also contributing to other aspects or units of their organizations. Lo et al., came up with similar findings whereby LMRs could prompt subordinates to behave more satisfactorily beyond their prescribed roles [7].

In comparing between first-line nurse managers and bedside nurses, nurse managers reported higher LMR ratings overall $(3.84 \pm 0.51)$ than bedside nurses $(3.66 \pm 0.59)$. This is in line with Maslyn and Uhl-Bien who maintained that there might be an adjustment as to the weighting of each dimension across individuals and leaders [20]. This exists when a subordinate's opinions are exchanged less constructively and more transactionally while a supervisor realizes the association more certainly. Here, a supervisor sees the relationship more favorably than a subordinate. It is possible that the subordinate misperceives the signals sent by a supervisor, or the supervisor is unsuccessful in his/her communication of the supervisor's positive regard for the subordinate. Alternatively, a supervisor's explanation as to the components of the relationship could be inflated by leniency.

"Loyalty" was perceived as moderately positive by nurses, which could be due to a feeling that managers need be more strident in their defense of employees when attacked, or advocate more for subordinates when an honest mistake is made. In order to enhance LMRs, leaders should treat employees as team members while monitoring interactions and exchange relationships [21]. Moreover, nurses should be aware that efficiency and effectiveness are important when taking care of patients. The present findings should be interpreted in light of prior findings showing that high LMR quality was reflected in high-perceived Loyalty $[22,23]$.

The "Respect" dimension was perceived the most positively within the present study. These results are in line with Farh et al., who observed that professional respect is perceived quite positively, emphasizing that when employees view their relationships with leaders as being high in professional respect, employees are more likely to comply with requests [24]. This could mean engaging in activities that may lead to overload in order to meet a manager's work goals.

In terms of work position, the findings showed that both nurses working at bedsides and management positions had positive LMR perceptions. Nevertheless, first line managers had more positive perceptions within the "Respect," "Affect," and "Contribution" domains. These results contradict those of Greguras and Ford whereby supervisors and subordinates appeared to assess LMRs similarly across all four domains [25]. According to the divergent pattern of LMR perceptions, domains need to be assessed from both perspectives (first line managers and bedside nurses) in order to produce a more comprehensive understanding of this phenomenon. Furthermore, according to Sagas and Cunningham, evolving and upholding high-quality relationships between a nurse manager and subordinate is very beneficial to the dyad, especially the subordinate [26]. High-quality LMRs are related to significant outcomes [2628]. To more ultimately appreciate a healthy work environment, employees must first be in harmony with their LMR awareness and their nursing managers.

\section{CONCLUSION}

The present findings revealed that nurses have positive LMR perceptions. However, nurse leaders must work more toward enhancing loyalty among staff nurses, which should better support the efficiency and effectiveness of patient care. In terms of personal and professional characteristics, the present results suggest that a nurse's staff position has a significant impact on his/her LMRs.

\section{RECOMMENDATIONS}

Cooperative efforts between administrative and clinical decision-makers are essential for setting policies and strategies designed to improve LMRs for individual nurses and other professionals. While nurses are in need of more autonomy, all aspects of patient-centered and professional-related issues should be considered through enhancing innovation, interdependency, and collaboration in order to foster clinical leadership development. To keep nurses oriented toward their relationships with superiors, as well as citizenship parameters, training and in-service orientation sessions are essential. Addressing all LMR constructs and their prerequisites for all nursing staff should lead to several beneficial outcomes, including creativity, job satisfaction, performance, and positive attitude adjustment. Nurse leaders must improve their interpersonal skills through in-service training in order to develop open and congruent relationships with their staff, which should be based on mutual trust, while providing subordinates opportunities to practice leadership skills each day. This should help develop a key group of second-line leaders. Further studies should be implemented in order to investigate LMRs across different healthcare providers (perhaps with junior nurses specifically) in order to determine strategies most suitable for enhancing employee commitment, loyalty, and positive attitudes toward leaders, organizations and the general profession. 


\section{LIMITATIONS}

Generalizability of the current study results should be taken with caution owing to the present findings being specific to one setting (Saudi hospital) and one category of participants (nurses). More comprehensive and diversified settings should be included in future research. It is also possible that LMR perceptions vary beyond the variables addressed in the present study. Unfortunately, most of the study participants were women who worked in general wards. Thus, the present findings cannot be generalized to other gender categories and non-hospital settings. Lastly, the present study focused on a set of selected personal and professional characteristics. Further characteristics within a hospital work environment will be useful for future study in order to clarify the LMR concept.

\section{ACKNOWLEDGEMENTS}

The authors are thankful to the Deanship of Scientific Research through the Research Center at the College of Nursing, King Saud University, for the support of this research project. Furthermore, we would like to thank the team at the Investigator Support Unit at Prince Naif Health Research Center in King Saud University Medical City for their support.

\section{REFERENCES}

1. Podsakoff, P. M., MacKenzie, S. B., \& Bommer, W. H. (1996).Transformational Leader Behaviors and Substitutes for Leadership as Determinants of Employee Satisfaction, Commitment, Trust, and Organizational Citizenship Behaviors. Journal of Management, 22(2), 259-298.

2. Hackett, R., Farh, J. L., Song, L., \& Lapierre, L. (2003). LMX and organizational citizenship behavior: Examining the links within and across Western and Chinese samples. In G. Graen (Ed.), Dealing with Diversity: LMX Leadership-The Series (pp. 219). Greenwich, CT: Information Age.

3. Organ, D. W. (1988). Organizational Citizenship Behavior: The Good Soldier Syndrome. Lexington, MA: Lexington Books/D. C. Heath and Com.

4. Volmer, J., Spurk, D., \& Niessen, C. (2012). Leader-member exchange (LMX), job autonomy, and creative work involvement. The Leadership Quarterly, 23(3), 456-465.

5. Boies, K., \& Howell, J. M. (2006). Leader-member exchange in teams: An examination of the interaction between relationship differentiation and mean LMX in explaining team-level outcomes. The Leadership Quarterly, 17(3), 246-257.

6. Liden, R. C., \& Maslyn, J. M. (1998). Multidimensionafity of Leader-Member Exchange: An Empirical Assessment through Scale Development. Journal of Management, 24(1), 43-72.

7. Lo, M. C., Ramayah, T., \& Kueh, J. (2006). An Investigation of Leader Member Exchange Effects on Organizational Citizenship Behavior in Malaysia. Journal of Business \& Management, 12, 5-23.

8. Leow, K. L., \& Khong, K. W. (2009). Organizational Commitment: The Study of Organizational Justice and Leader Member Exchange (LMX) Among Auditors in Malaysia. International Journal of Business and Information, 4(2), 161-198.

9. Scandura, T. A., \& Pellegrini, E. K. (2007). Workplace mentoring: Theoretical approaches and methodological issues The Blackwell handbook of mentoring: A multiple perspectives approach. (pp. 71-91). Malden: Blackwell Publishing.

10. Goldberg, C., \& McKay, P. F. (2015). Diversity and LMX Development. The Oxford Handbook of Leader-Member Exchange.

11. Polit, D. F., \& Beck, C. T. (2014). Essentials of Nursing Research: Appraising Evidence for Nursing Practice (8th ed.). Philadelphia: Lippincott Williams \& Wilkins.

12. Frey, L. R., Botan, C. H., \& Kreps, G. L. (2000). Investigating Communication: An Introduction to Research Methods. (2nd ed.). Boston: Allyn and Bacon.

13. American Health Care Association. (2012). Staffing Survey Report. Retrieved October 7, 2019, from https://www.ahcancal.org/research_data/staffing/Documents/2011\%20Staffing\%20Survey\%20Report.pdf

14. Mallory, D. B., Rupp, D. E., Bauer, I. T., \& Erdogan, B. (2014). "Good" leadership: Using corporate social responsibility to enhance leader-member exchange. Paper presented at the Annual Meeting of the Society for Industrial and Organizational Psychology, Honolulu, HI.

15. Almasradi, R. B., Panatik, S. A., \& Chikaji, A. I. (2017). The Relationship Between LMX and OCB in Saudi Arabia-Review of Literature. Advanced Science Letters, 23(9), 8843-8845.

16. Schyns, B. (2008). Follower characteristics and the perception of leader-member exchange. Journal of Managerial Psychology, 23(7), 772-788.

17. Dunegan, K. J., Uhl-Bien, M., \& Duchon, D. (2002). LMX and subordinate performance: The moderating effects of task characteristics. Journal of Business and Psychology, 17(2), 275-285.

18. Chen, C. H., Wang, S. J., Chang, W. C., \& Hu, C. S. (2008). The effect of leader-member exchange, trust, supervisor support on organizational citizenship behavior in nurses. The Journal of Nursing Research, 16(4), 321-328.

19. Organ, D. W., \& Konovsky, M. (1989). Cognitive versus affective determinants of organizational citizenship behavior. Journal of Applied Psychology, 74(1), 157-164.

20. Maslyn, J. M., \& Uhl-Bien, M. (2001). Leader-member exchange and its dimensions: effects of self-effort and other's effort on relationship quality. Journal of Applied Psychology, 86(4), 697-708. 
21. Rosen, C. C., Harris, K. J., \& Kacmar, K. M. (2010). LMX, Context Perceptions, and Performance: An Uncertainty Management Perspective. Journal of Management, 37(3), 819-838.

22. Harris, K. J., Wheeler, A. R., \& Kacmar, K. M. (2009). Leader-member exchange and empowerment: Direct and interactive effects on job satisfaction, turnover intentions, and performance. The Leadership Quarterly, 20(3), 371-382.

23. Morrow, P. C., Suzuki, Y., Crum, M. R., Ruben, R., \& Pautsch, G. (2005). The role of leader-member exchange in high turnover work environments. Journal of Managerial Psychology, 20(8), 681-694.

24. Farh, J.-L., Hackett, R. D., \& Liang, J. (2007). Individual-Level Cultural Values as Moderators of Perceived Organizational Support-Employee Outcome Relationships in China: Comparing the Effects of Power Distance and Traditionality. The Academy of Management Journal, 50(3), 715-729.

25. Greguras, G. J., \& Ford, J. M. (2006). An examination of the multidimensionality of supervisor and subordinate perceptions of leader-member exchange. Journal of Occupational and Organizational Psychology, 79(3), 433-465.

26. Sagas, M., \& Cunningham, G. B. (2004). Treatment Discrimination in College Coaching: Its Prevalence and Impact on the Career Success of Assistant Basketball Coaches. International Sports Journal, 8(1), 76-88.

27. Masterson, S. S., Lewis, K., Goldman, B. M., \& Taylor, M. S. (2000). Integrating Justice and Social Exchange: The Differing Effects of Fair Procedures and Treatment on Work Relationships. The Academy of Management Journal, 43(4), 738-748.

28. Pillai, R., Scandura, T., \& Williams, E. (1999). Leadership and Organizational Justice: Similarities and Differences across Cultures. Journal of International Business Studies, 30(4), 763-779. 